\title{
INVESTIGATIONS OF SOME PROPERTIES OF MATERIAL SAMPLES TAKEN FROM THE AIRCRAFT WITHDRAWN FROM SERVICE
}

\author{
Sylwester Klysz \\ Gabriel Gmurczyk \\ Janusz Lisiecki
}

Air Force Institute of Technology, Warsaw, Poland

\begin{abstract}
Materials used in aircraft structures have (should have) certificates confirming their quality. Nowadays, in majority of cases, the symbols of materials used in construction of aircraft give detailed information about their mechanical properties. This general material data is gathered in the widely available engineering material data bases. In the case of materials used in Polish aviation several decades ago, there is no reliable material data crucial for crack propagation estimation or fatigue life estimation among others. Examinations conducted in many different research institutes are not systematized and are not gathered in a remotely accessible data base.

As aging aircraft are concerned, the influence of service time (often exceeding thirty years) on the overall material properties is a very important factor. It may be too crude estimation to use standard material properties when it comes to aging aircraft fleet. Some experimental works concerning this topic are published from time to time and they are always very welcome.

In the Air Force Institute of Technology experimental tests were carried out to determine some specific properties of the materials used in the PZL-130 Orlik aircraft structure. The samples were obtained from aircraft withdrawn from service. This enabled estimating the difference in material properties over time. The following tests were conducted during the experiments:

- fatigue tests (crack propagation examination)

- $\quad$ static tests.

The analyzed material was taken from the central upper part of the aircraft wing. The experiment was conducted with the MTS machine with the 810.23 system.
\end{abstract}

\section{INTRODUCTION}

For aging aircraft structures, the influence of service time (often exceeding thirty years) on the material properties is a very important issue. Some experimental works concerning this problem are published from time to time and they are always very welcome. Material properties data bases, concerning in particular fatigue durability, are a crucial source of information for aircraft designers and users. Material fatigue is a very important issue in aviation owing to the peculiarity of aircraft structure, which is designed according to the aircraft mass optimization criteria. This leads to strain on structure and affects structure durability.

Nowadays, in many cases, aircraft and helicopters are used beyond designed service time. Because of huge cost, it is not possible to immediately replace an aging aircraft fleet with a new 
one. Many investigations are conducted all over the world to enable extending aircraft service time [1].

In particular, this concerns material properties. In the case of the PZL-130 Orlik aircraft lack of sufficient material information causes much difficulty. During design and production of this aircraft, the data gathered on the materials and their properties were insufficient, especially from the extended operating period point of view.

Another problem related to the properties of the materials used is their degradation. Many works suggest that the material properties' degradation should be taken into consideration in aircraft structural integrity programs [2]. Currently, changing the way and system of aircraft exploitation, we have to complete the data available with materials investigations necessary for residual fatigue strength estimation and determination of aircraft structure nondestructive inspections periods. These investigations are lengthy and expensive, but their lack makes the necessary analyses impossible.

In the Air Force Institute of Technology experimental test were carried out to determine some specific properties of the materials used in the PZL-130 Orlik aircraft structure. The samples were obtained from aircraft taken out of service. The following tests were conducted during the experiments:

- fatigue tests (crack propagation examination),

- $\quad$ static tests.

The analyzed material was taken from the central upper part of the aircraft wing. The experiment was conducted with the MTS machine with the 810.23 system.

\section{MATERIALS WITHDRAWN FROM THE OPERATION TESTS}

Material research, collection and validation of the data obtained represent a significant asset of industry research centers. The Air Force Institute of Technology with its accredited Laboratory of Materials Strength and access to aircraft withdrawn from exploitation, is one of the leading scientific centers in Poland carrying out specific research on fatigue of materials. At this laboratory, the static tests of the material and fatigue-crack propagation rate research were performed. Samples were collected from the wing of the end-of life PZL-130 TC-I (Fig. 1). Figure 2 shows fragments of the shell from which the samples were collected for static tensile tests. Figure 3 shows the distribution of RCT specimens for fatigue tests of the shell element. The samples were performed in the AFIT Department of Prototyping.

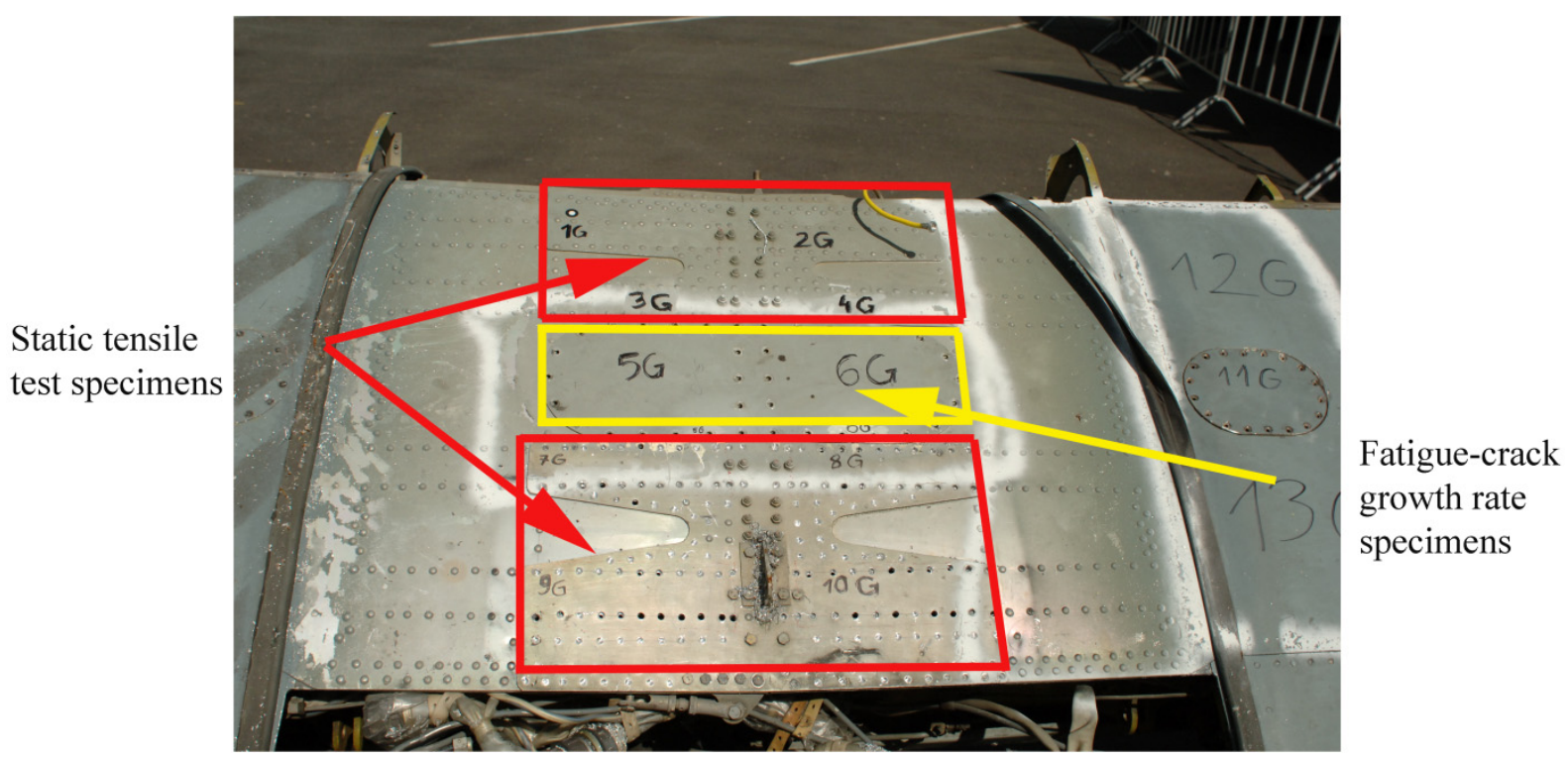

Figure 1. The wing of the PZL-130 - place of collecting material for specimens 


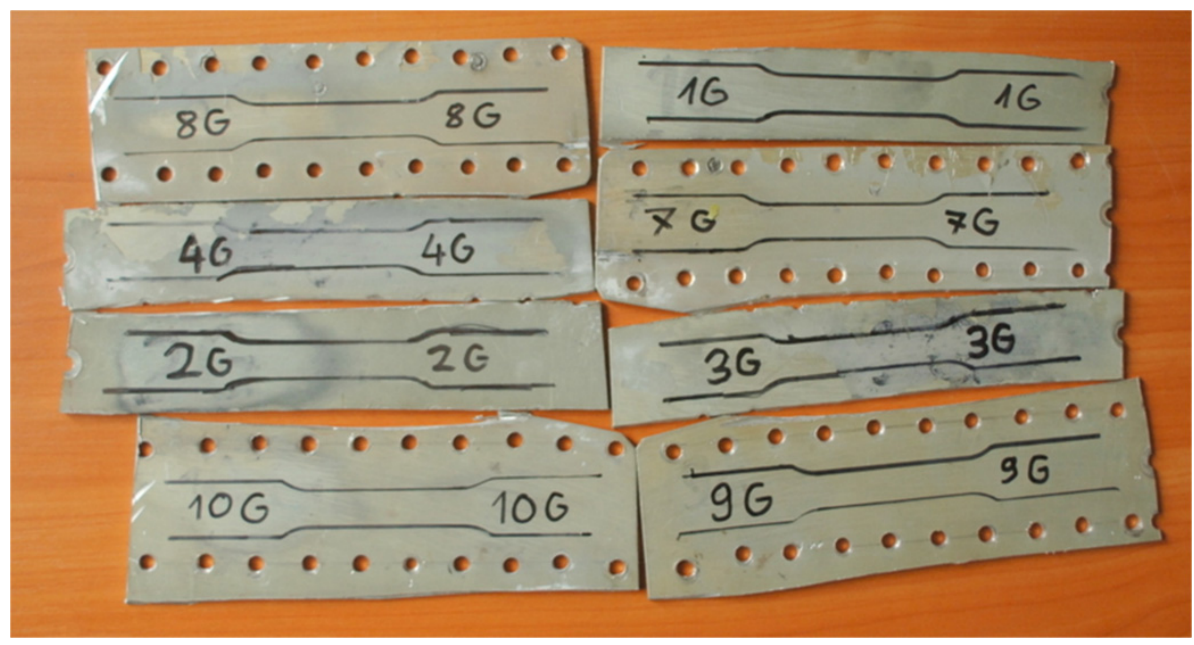

Figure 2. Location of collecting static test specimens

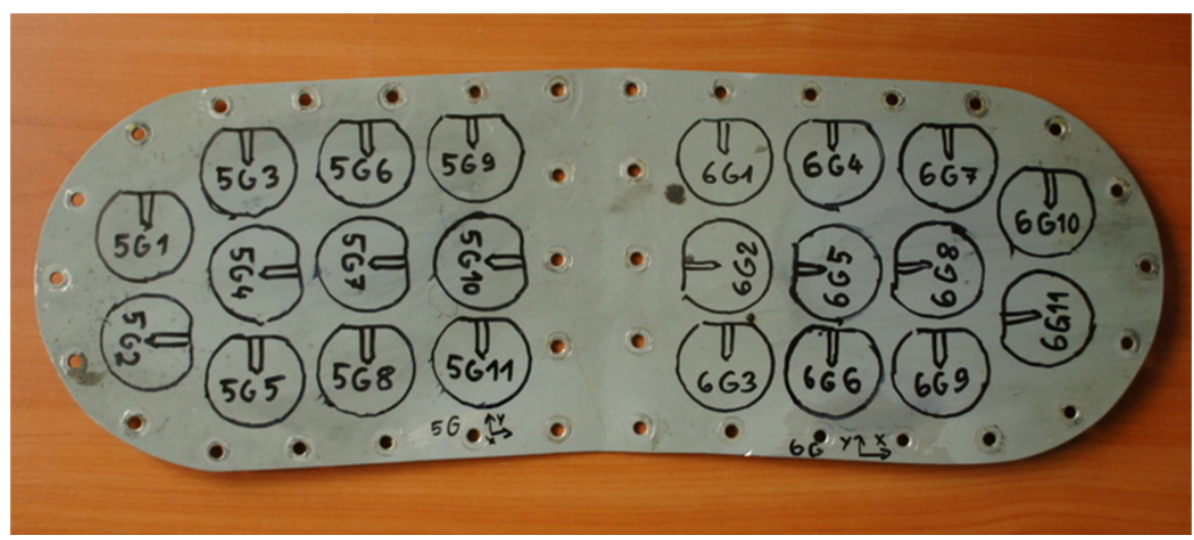

Figure 3. Distribution of fatigue-crack growth rate specimens

\section{STATIC TENSILE TEST}

The static tensile tests [3], for the population of eight specimens made of material taken from the overlay on the upper shell of the central wing (Fig. 2) were performed using the testing machine MTS 810.23. To measure the deformation, a strain extensometer MTS and a videoextensometr - ME 46 MessPhysik worked simultaneously. The specimens dimensions were: gauge length $50 \mathrm{~mm}$, width $12.5 \mathrm{~mm}$ and thickness $1.2 \mathrm{~mm}$. The measurement results are presented in Tables 1 and 2.

Table 1. The measurement results of static tensile test

\begin{tabular}{|c|c|c|c|c|c|c|c|c|c|}
\hline \multirow{2}{*}{ Specimen No. } & $a_{0}$ & $b_{0}$ & $L_{0 v e}$ & $R_{0,01}$ & $R_{0,05}$ & $R_{0,2}$ & $R_{m}$ & $A_{50 \mathrm{~mm}}$ & $E$ \\
\cline { 2 - 10 } & {$[\mathrm{mm}]$} & {$[\mathrm{mm}]$} & {$[\mathrm{mm}]$} & {$[\mathrm{MPa}]$} & {$[\mathrm{MPa}]$} & {$[\mathrm{MPa}]$} & {$[\mathrm{MPa}]$} & {$[\%]$} & {$[\mathrm{MPa}]$} \\
\hline $5 / 09 / 1(8 \mathrm{G})$ & 2,73 & 12,37 & 50,42 & 209 & 237 & 259 & 416 & 19,4 & 76700 \\
\hline $5 / 09 / 2(4 \mathrm{G})$ & 2,73 & 12,35 & 49,99 & 208 & 229 & 255 & 413 & 19,2 & 59900 \\
\hline $5 / 09 / 3(2 \mathrm{G})$ & 2,73 & 12,41 & 50,01 & 208 & 242 & 261 & 45 & 18,9 & 67800 \\
\hline $5 / 09 / 4(10 \mathrm{G})$ & 2,73 & 12,42 & 49,95 & 206 & 243 & 262 & 413 & $-*$ & 79500 \\
\hline $5 / 09 / 6(1 \mathrm{G})$ & 2,73 & 12,40 & 49,87 & 222 & 242 & 260 & 413 & 18,5 & 61800 \\
\hline $5 / 09 / 7(3 \mathrm{G})$ & 2,73 & 12,29 & 50,23 & 232 & 250 & 268 & 418 & $-*$ & 65400 \\
\hline
\end{tabular}

* Failure outside the gauge length;

$\mathrm{L}_{0 \mathrm{ve}}$ - measuring range of video-extensometer;

$\mathrm{A}_{50 \mathrm{~mm}}$ - set on the basis of video-extensometer indications. 
Table 2. Measurement of percentage elongation after fracture, based on the segments of the initial gauge length

\begin{tabular}{|c|c|c|c|c|c|c|c|}
\hline \multirow{2}{*}{ Specimen No. } & $L_{0}$ & $L_{u}$ & $X Y$ & $Y Z$ & $Y Z^{\prime}$ & $Y Z^{\prime \prime}$ & $A_{50 \mathrm{~mm}}$ \\
\cline { 2 - 8 } & {$[\mathrm{mm}]$} & {$[\mathrm{mm}]$} & {$[\mathrm{mm}]$} & {$[\mathrm{mm}]$} & {$[\mathrm{mm}]$} & {$[\mathrm{mm}]$} & {$[\%]$} \\
\hline $5 / 09 / 1(8 \mathrm{G})$ & 50,082 & 60,800 & - & - & - & - & 21,4 \\
\hline $5 / 09 / 2(4 \mathrm{G})$ & 49,929 & 59,791 & - & - & - & - & 19,8 \\
\hline $5 / 09 / 3(2 \mathrm{G})$ & 49,985 & 59,828 & 18,782 & - & 17,650 & 23,486 & 20,0 \\
\hline $5 / 09 / 4(10 \mathrm{G})$ & 50,037 & - & \multicolumn{7}{|c|}{ Failure outside the gauge length } & - \\
\hline $5 / 09 / 6(1 \mathrm{G})$ & 50,018 & 59,778 & \multicolumn{7}{|c|}{19,242} & - & 17,437 & 23,251 & 19,8 \\
\hline $5 / 09 / 7(3 \mathrm{G})$ & 49,946 & - & \multicolumn{7}{|c|}{ Failure outside the gauge length } & - \\
\hline
\end{tabular}

$\mathrm{L}_{0}$ - initial gauge length between the segments;

$\mathrm{L}_{\mathrm{u}}$ - final gauge length between the segments.

An example of static tensile stress-deformation curve is shown in Figure 4. The specimen 5/09/1 (8G) after fracture is shown in Figure 5.

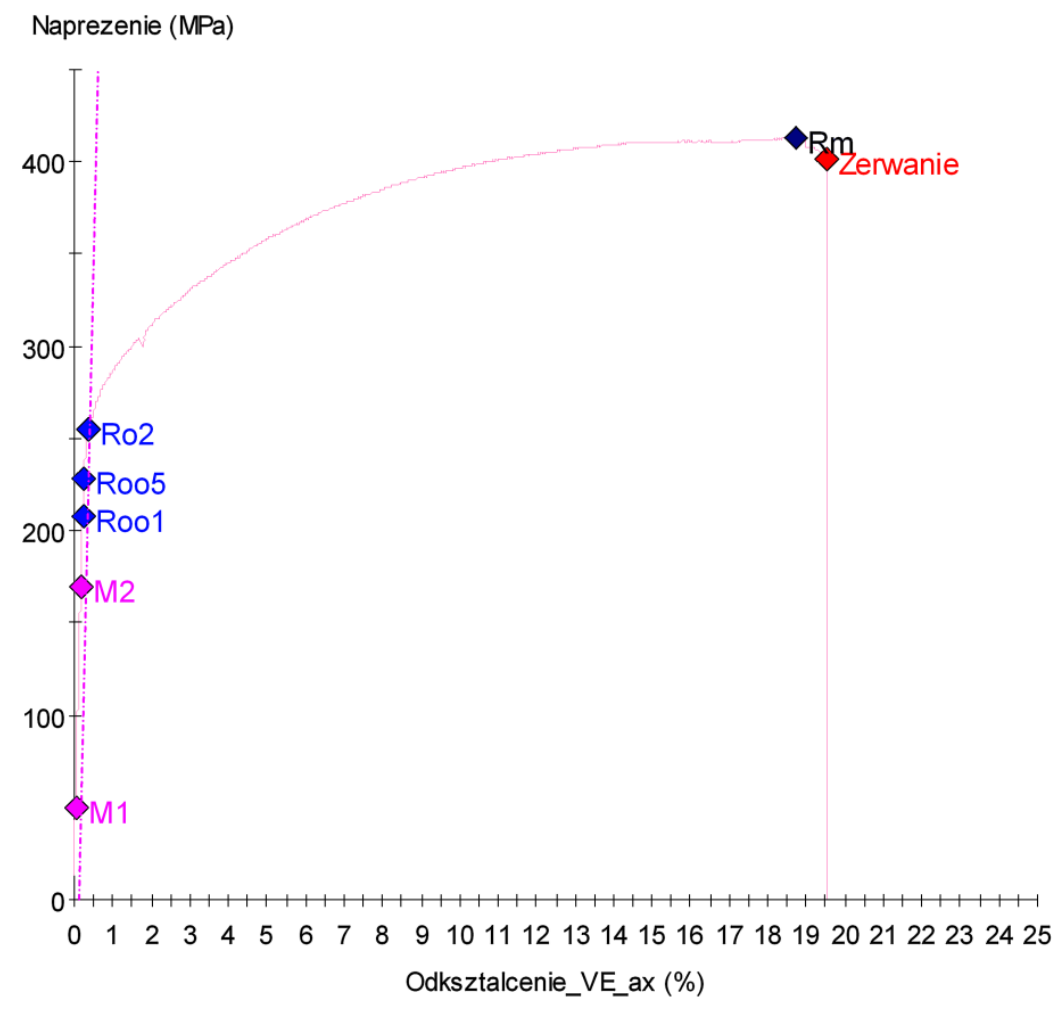

Figure 4. Static tensile test diagram of the sample 5/09/4 (10G)

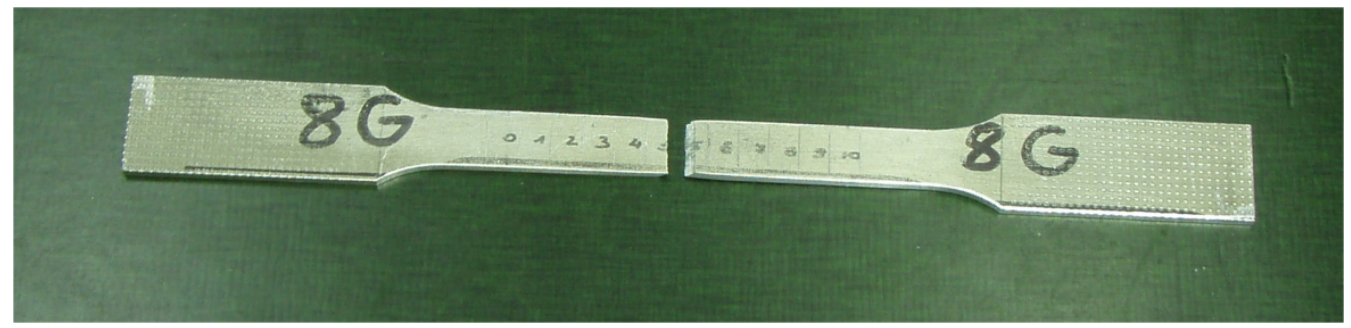

Figure 5. The No 5/09/1 (8G) Specimen after test 


\section{THE STUDY OF CRACK GROWTH RATE}

Studies of fatigue crack growth rate were carried out on sixteen compact type RCT specimens (thickness $1.95 \mathrm{~mm}$, equal to the thickness of the lid) (Fig. 3). The tests were carried out according to the test procedure PB-5/31 LBWM [4] using the testing machine MTS 810.23. The frequency of cyclic loads was $15 \mathrm{~Hz}$. The samples were tested with the cycles of the three values of the stress ratio $R=0.1,0.5$, and 0.8 . Each sample was tested in two stages - in the test range with decreasing $\Delta K$ (threshold propagation area of the curve $d a / d N=f(\Delta K)$ ) and in the test of constant amplitude (critical area of the curve, to break the sample). To determine the crack length, the COD MTS extensometer was used. To measure the crack length, the vulnerability method was applied, and to determine the speed of crack propagation $d a / d N$, the polynomial method was used. Test results are presented in Table 3. The table contains, based on experimental data, Paris equation coefficients $m$ and $C$ which describe the propagation curves. Fig.6 shows examples of graphs of the MTS machine $(a=f(N), K=f(N)$ and $d a / d N=f(\Delta K))$. Figure 7 shows an example of the specimen of $5 / 09 / 10(5 \mathrm{G} 2)$ after testing.

Table 3. Test results

\begin{tabular}{|c|c|c|c|c|c|c|c|c|c|c|}
\hline & & & & & \multicolumn{3}{|c|}{ DK decreasing test } & \multicolumn{3}{|c|}{ Constant Amplitude CA test } \\
\hline $\begin{array}{c}\text { Specimen } \\
\text { No. }\end{array}$ & $\mathrm{m}$ & $\mathrm{C}$ & $\begin{array}{c}\mathrm{N} \\
{[\text { cycle] }}\end{array}$ & $\begin{array}{c}\mathrm{a} \\
{[\mathrm{mm}]}\end{array}$ & $\begin{array}{c}\Delta \mathrm{K}_{\mathrm{start}} \\
{[M P a \sqrt{m]}}\end{array}$ & $\begin{array}{c}\Delta \mathrm{K}_{\text {finish }} \\
{[M P a \sqrt{m}]}\end{array}$ & $\begin{array}{c}\mathrm{N} \\
{[\text { cycle] }}\end{array}$ & $\begin{array}{c}\mathrm{a} \\
{[\mathrm{mm}]}\end{array}$ & $\begin{array}{c}\Delta \mathrm{K}_{\text {start }} \\
{[M P a \sqrt{m}]}\end{array}$ & $\begin{array}{c}\Delta \mathrm{K}_{\text {finish }} \\
{[M P a \sqrt{m]}}\end{array}$ \\
\hline $\begin{array}{l}5 / 09 / 10 \\
(5 \mathrm{G} 2 \mathrm{P})\end{array}$ & 4,6880 & $1,708 \mathrm{E}-09$ & 840119 & 12,4 & 14,8 & 4,3 & 1311589 & 22,6 & 4,7 & 27,1 \\
\hline $\begin{array}{c}5 / 09 / 11 \\
(5 \mathrm{G} 3 \mathrm{~W})\end{array}$ & 4,0064 & $1,00 \mathrm{E}-03$ & 1203855 & 10,7 & 6,5 & 3,5 & 2658864 & 21,5 & 3,1 & 16,0 \\
\hline $\begin{array}{l}5 / 09 / 12 \\
(5 \mathrm{G} 4 \mathrm{P})\end{array}$ & 2,9344 & $1,00 \mathrm{E}-03$ & 2072501 & 8,9 & 2,7 & 1,5 & 4027008 & 18,3 & 2,1 & 6,8 \\
\hline $\begin{array}{l}5 / 09 / 13 \\
(5 \mathrm{G} 5 \mathrm{~W}) \\
\end{array}$ & 3,7289 & $1,247 \mathrm{E}-07$ & 3430343 & 9,2 & 2,4 & 1,3 & 5318180 & 18,3 & 1,9 & 5,7 \\
\hline $\begin{array}{l}5 / 09 / 14 \\
(5 \mathrm{G} 6 \mathrm{~W}) \\
\end{array}$ & 2,8153 & $2,079 \mathrm{E}-07$ & 2251292 & 8,7 & 2,7 & 1,6 & 4104500 & 18,4 & 2,2 & 7,1 \\
\hline $\begin{array}{l}/ 09 / 15 \\
(5 \mathrm{G} 7 \mathrm{P}) \\
\end{array}$ & 3,5479 & $5,569 \mathrm{E}-08$ & 1258899 & 11,3 & 6,5 & 2,1 & 2441518 & 21,8 & 2,8 & 13,9 \\
\hline $\begin{array}{l}5 / 09 / 16 \\
(5 \mathrm{G} 8 \mathrm{~W}) \\
\end{array}$ & 4,5524 & $1,796 \mathrm{E}-09$ & 804594 & 12,5 & 15,2 & 4,5 & 1218128 & 22,4 & 5,3 & 27,0 \\
\hline $\begin{array}{l}5 / 09 / 17 \\
(5 \mathrm{G} 9 \mathrm{~W}) \\
\end{array}$ & 4,3706 & $5,667 \mathrm{E}-09$ & 877972 & 13,5 & 14,1 & 5,3 & 1125009 & 21,6 & 5,3 & 19,7 \\
\hline $\begin{array}{l}5 / 09 / 20 \\
(6 \mathrm{G} 1 \mathrm{~W}) \\
\end{array}$ & 2,6219 & $2,398 \mathrm{E}-07$ & 2490962 & 9,0 & 2,7 & 1,5 & 4618199 & 18,8 & 2,0 & 6,9 \\
\hline $\begin{array}{l}5 / 09 / 20 \\
(6 \mathrm{G} 1 \mathrm{~W}) \\
\end{array}$ & 4,2704 & $7,181 \mathrm{E}-09$ & 1171257 & 14,3 & 14,7 & 3,4 & 1234447 & 22,1 & 5,7 & 7,9 \\
\hline $\begin{array}{l}5 / 09 / 20 \\
(6 \mathrm{G} 1 \mathrm{~W}) \\
\end{array}$ & 4,0501 & $1,500 \mathrm{E}-08$ & 985100 & 13,4 & 14,4 & 3,1 & 1104883 & 21,6 & 5,0 & 18,2 \\
\hline $\begin{array}{l}5 / 09 / 20 \\
(6 \mathrm{GlW}) \\
\end{array}$ & 3,7797 & $5,449 \mathrm{E}-09$ & 934667 & 13,9 & 14,9 & 3,9 & 1375344 & 22,0 & 4,7 & 33,8 \\
\hline $\begin{array}{l}5 / 09 / 20 \\
(6 \mathrm{G} 1 \mathrm{~W}) \\
\end{array}$ & 3,8440 & $5,587 \mathrm{E}-08$ & 836681 & 11,2 & 6,3 & 2,1 & 1685247 & 21,0 & 2,7 & 11,5 \\
\hline $\begin{array}{l}5 / 09 / 20 \\
(6 \mathrm{G} 1 \mathrm{~W}) \\
\end{array}$ & 3,1478 & $1,349 \mathrm{E}-07$ & 2081698 & 8,5 & 2,7 & 1,7 & 4427581 & 18,5 & 2,1 & 7,3 \\
\hline $\begin{array}{l}5 / 09 / 20 \\
(6 \mathrm{G} 1 \mathrm{~W}) \\
\end{array}$ & 4,4192 & $5,206 \mathrm{E}-09$ & 830914 & 13,2 & 14,3 & 4,9 & 1100788 & 22,0 & 4,9 & 19,7 \\
\hline $\begin{array}{r}5 / 09 / 20 \\
(6 \mathrm{G} 1 \mathrm{~W}) \\
\end{array}$ & 3,8739 & $2,641 \mathrm{E}-08$ & 1196023 & 10,6 & 6,5 & 2,5 & 2001889 & 21,2 & 3,3 & 15,2 \\
\hline
\end{tabular}



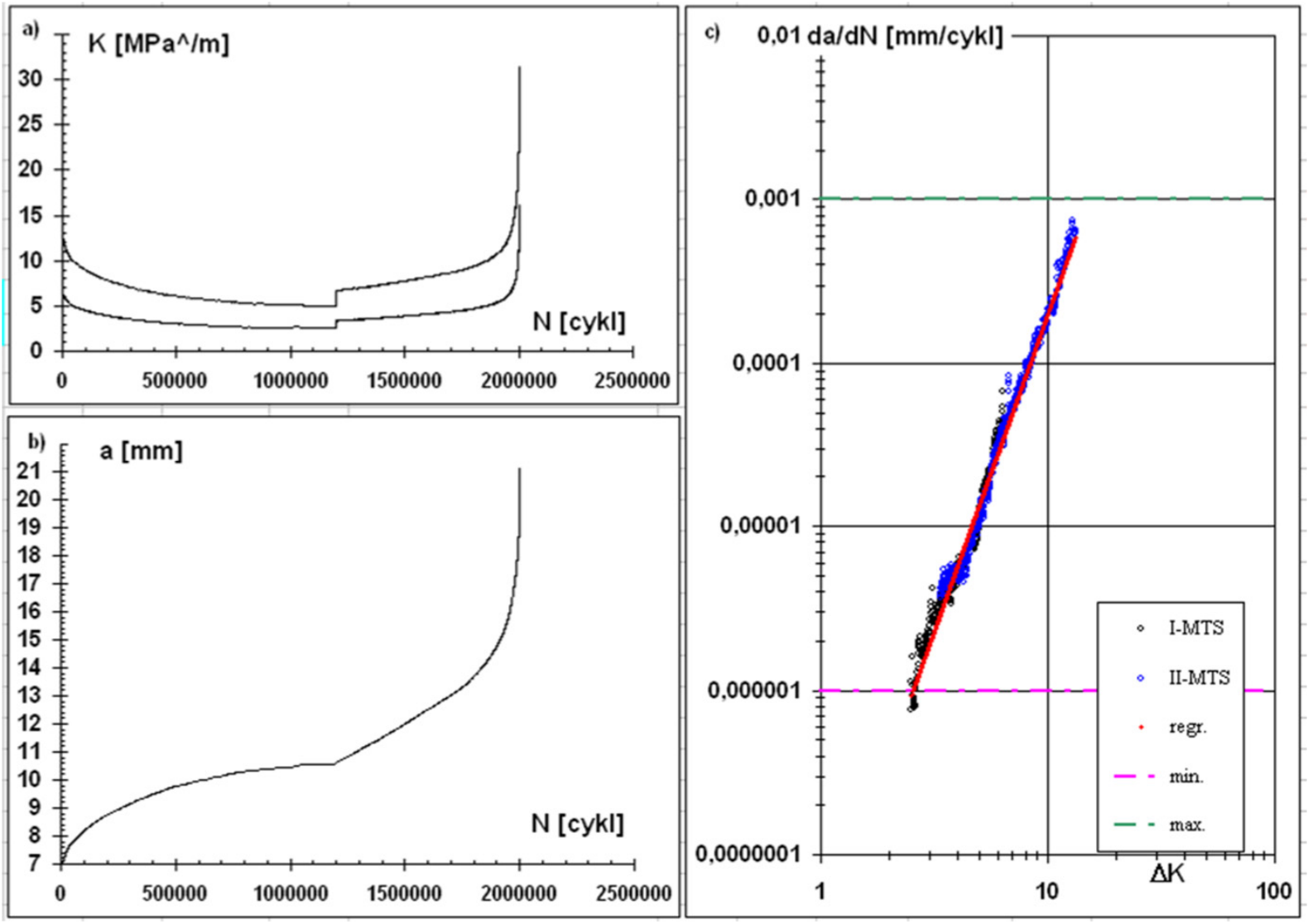

Figure 6. $K=f(N), a=f(N)$ and $d a / d N=f(\Delta K)$ - diagram for sample $5 / 09 / 30(6 G 11)$

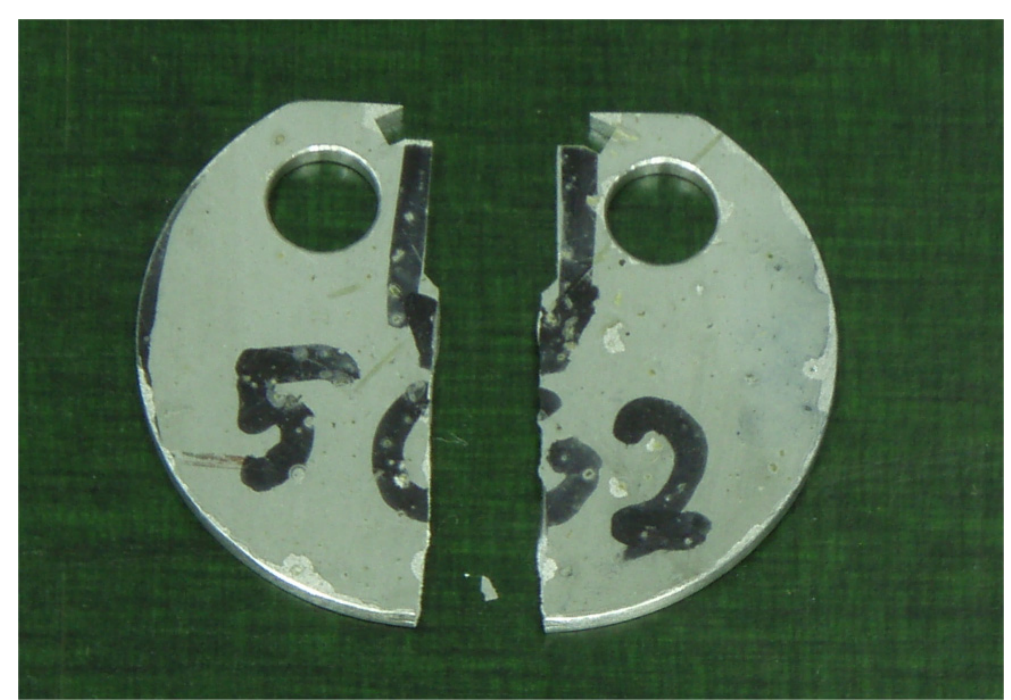

Figure 7. Compact type RCT specimen 5/09/10 (5G2) after testing

Figure 8 shows the $d a / d N=f(\Delta K)$ for the nine samples (3 samples for each $R$ ) and the description of the curves obtained from the NASGRO propagation equation. NASGRO equation coefficients are given in the table. 


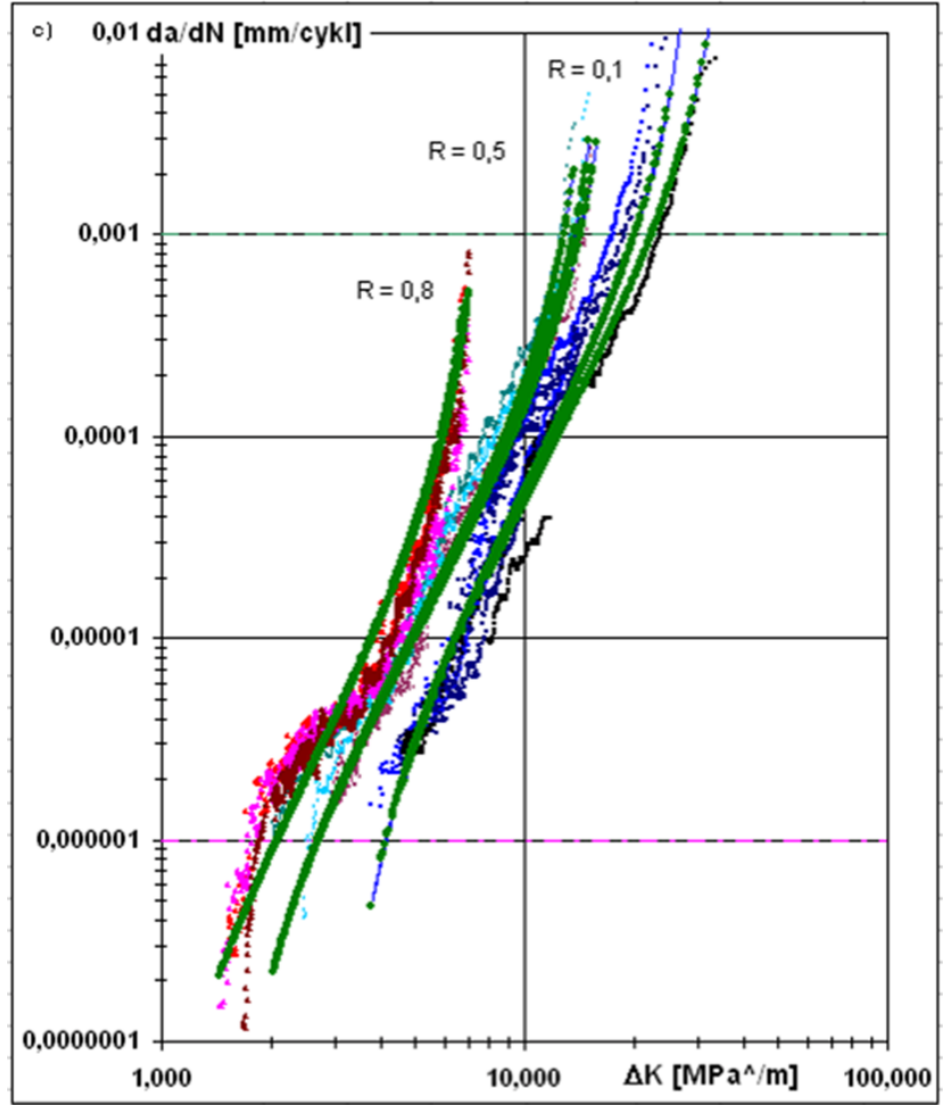

\begin{tabular}{|c|c|c|c|c|c|c|c|c|}
\hline $\boldsymbol{\alpha}$ & $\sigma_{\max } / \boldsymbol{\sigma}_{\mathbf{o}}$ & $\Delta \mathbf{K}_{\mathbf{o}}$ & $\mathbf{a}$ & $\mathbf{C}_{\text {th }}$ & $\mathbf{n}$ & $\mathbf{p}$ & $\mathbf{q}$ & $\mathbf{C}$ \\
\hline 3,73179 & 0,997 & 4,003846 & 0,0000381 & 30,38025 & 2,550 & 1,974 & 1,132 & $1,846 \mathrm{E}-07$ \\
\hline
\end{tabular}

Figure 8. NASGRO equation coefficients for specimens collected from the airframe of PZL-130 TC-I after operation

\section{SUMMARY}

The presented results are the first step in examining the impact of the operation of the PZL-130 Orlik on the properties of the materials used. The second step covers the study of not exploited material properties and comparison the results with the results obtained in the first step, and a broad analysis of the results of fatigue tests based on the fitting curves obtained from the NASGRO propagation equation.

\section{REFERENCES}

[1] Forman, R., G. \& all (2005). Fatigue Crack Growth Database for Damage Tolerance Analysis. FAA, Waszyngton

[2] Nesterenko, G., I. Investigation of material properties degradation in operated airplanes structures. 9th Joint FAA/DoD/NASA Aging Aircraft Conference

[3] Norma PN-EN 10002-1:2004. Metale. Próba rozciagania. Część 1: Metoda badania w temperaturze otoczenia

[4] Procedura Laboratorium Badań Wytrzymałościowych Materiałów ITWL nr PB-5/31 